\title{
Recreational Drug Use Among Primary Care Patients: Implications of a Positive Self-Report
}

\author{
Judith Bernstein, RNC, $P b D^{1,2}$ \\ Debbie M. Cheng, $S_{c} D^{3,4}$ \\ $\mathrm{Na}$ Wang, $M A^{5}$ \\ Caitlin Trilla, $M S^{4}$ \\ Jeffrey Samet, MD, MA, MPH \\ Richard Saitz, MD, MPH ${ }^{1,4}$
}

'Department of Community Health Sciences, Boston University School of Public Health, Boston, Massachusetts

${ }^{2}$ Department of Emergency Medicine, Boston University School of Medicine, Boston, Massachusetts

${ }^{3}$ Department of Biostatistics, Boston University School of Public Health, Boston, Massachusetts

${ }^{4}$ Clinical Addiction Research and Education Unit, Section of General Internal Medicine, Department of Medicine, Boston Medical Center, Boston University School of Medicine, Boston, Massachusetts

${ }^{5}$ Data Coordinating Center, Boston University School of Public Health, Boston, Massachusetts

Conflicts of interest: authors report none.

\section{CORRESPONDING AUTHOR}

Judith Bernstein, RNC, PhD, Professor of Community Health Sciences Boston University School of Public Health 801 Massachusetts Ave. \#431B

Boston, MA 02118

jbernste@bu.edu

\begin{abstract}
Should recreational drug use raise clinical concern? We examined the association between weekend-only recreational drug use at baseline (yes vs no) and any increase in recreational drug use frequency or severity over 6 months among primary care patients who screen positive for drug use. In the weekend-only recreational drug use group (52/483 [10.8\%]), 54\% (28/52) started using drugs on weekdays. Compared with use not limited to weekends, weekend-only use was associated with lower odds of increasing drug use frequency (AOR 0.48, $P=0.03$ ) and lower odds (non-significant) of increasing severity (AOR 0.56, $P=0.07$ ). Although weekend-only recreational drug use appears prognostically less severe, the findings nonetheless suggest that continued episodic monitoring may be clinically wise.
\end{abstract}

Ann Fam Med 2015;13:257-260. doi: 10.1370/afm.1750.

\section{INTRODUCTION}

Tlegal drug use among primary care patients is estimated at $5 \%$ to $8 \%^{1}$ but often goes undetected. ${ }^{2}$ The physical, emotional, and social risks of recreational drug use are not well understood, but any drug use, even occasional use, may have an impact on disease processes and the effectiveness of prescribed medications. For this reason, and given the potential for sporadic drug use to increase, primary care physicians have a "need to



The aims of this study were to describe the pattern of use over 6 months for primary care patients who reported weekend-only drug use (ie, use only on Fridays, Saturdays, or Sundays) at enrollment compared with those whose use was not limited to weekends and to evaluate the association between weekend-only drug use at baseline and subsequent drug use and consequences. Clinicians need to know whether an initial report of recreational drug use is benign or has potential prognostic significance of clinical concern.

\section{METHODS}

\section{Design}

This study is a secondary analysis of data collected from adult patients $(\mathrm{N}=529)$ presenting for a primary care office visit at Boston Medical Center from 2009 to 2011 and enrolled in a trial of brief interventions for drug use (Assessing Screening Plus Brief Intervention's Resulting Efficacy to Stop Drug Use (ASPIRE), which did not detect differences by intervention status. ${ }^{4}$

\section{Sample}

We included in this analysis all enrollees in the main ASPIRE study who reported using drugs in the previous month and completed a follow-up visit at 6 months post enrollment. The ASPIRE study enrolled $60 \%$ of eligible patients and had a follow-up rate of $98 \%$ at 6 months. 


\section{MEASUREMENT INSTRUMENTS}

Data collected at baseline and 6 months included a global ASSIST (Alcohol, Smoking and Substance Involvement Screening Test) score ${ }^{5}$ as a measure of severity and the self-reported number of days of use of the drug of most concern, using the Timeline Followback method. ${ }^{6}$ Standardized clinical instruments (Table 1) were used to assess health status, unhealthy alcohol use, drug use consequences, anxiety, and depressive symptoms. ${ }^{4}$

\section{Statistical Analyses}

Descriptive statistics were used to characterize subjects overall and stratified by weekend-only use vs notweekend-only use. The primary analyses used separate logistic regression models for each dependent variable, controlling for age, race, Hispanic ethnicity, sex, education, alcohol use, employment, anxiety, health status, randomization status, and baseline value of the outcome. All analyses were conducted using two-sided tests and a significance level of 0.05. Analysis was performed using SAS 9.3 (SAS Institute, Inc.).

\section{RESULTS}

\section{Demographic Characteristics and Type of Drug Use Among Primary Care Patients}

The study sample (Table 1) consisted of 483 patients who were primarily male and African American, with a mean age of 41.6 years, and English as their primary language. Only $11.6 \%$ identified as Hispanic. Drugs most commonly used included marijuana, cocaine, and opioids. The mean for drug severity, measured by a global ASSIST score, was below the cutoff for dependence, and the median number of days of use per month of the drug of most concern in the last 30 days

Table 1. Baseline Characteristics, Health Status, and Drug Use by Weekend-Only vs Not-Weekend-Only Drug Use

\begin{tabular}{|c|c|c|c|c|}
\hline Variables & $\begin{array}{c}\text { Total } \\
(n=483)\end{array}$ & $\begin{array}{l}\text { Weekend-Only Use } \\
(\mathrm{n}=52)\end{array}$ & $\begin{array}{l}\text { Not-Weekend-Only Use } \\
\qquad(\mathrm{n}=431)\end{array}$ & $P$ Value \\
\hline Age in years, mean (SD) & $41.6(12.4)$ & $44.5(12.8)$ & $41.3(12.3)$ & .07 \\
\hline Female, n (\%) & 151 (31.3\%) & $14(26.9 \%)$ & $137(31.8 \%)$ & .47 \\
\hline \multicolumn{5}{|l|}{ Race, n (\%) } \\
\hline White & $95(19.7 \%)$ & $9(17.3 \%)$ & $86(20.0 \%)$ & .65 \\
\hline African American & $316(65.4 \%)$ & $36(69.2 \%)$ & $280(65.0 \%)$ & .54 \\
\hline Hispanic & $56(11.6 \%)$ & $5(9.6 \%)$ & $51(11.8 \%)$ & .64 \\
\hline Primary language English, n (\%) & $446(92.3 \%)$ & $48(92.3 \%)$ & $398(92.3 \%)$ & $>.99$ \\
\hline Continental United States born, n (\%) & $419(86.7 \%)$ & $42(80.8 \%)$ & $377(87.5 \%)$ & .18 \\
\hline High school graduation or more, $\mathrm{n}(\%)$ & $336(69.6 \%)$ & $33(63.5 \%)$ & $303(70.3 \%)$ & .31 \\
\hline $1+$ nights past 3 months on street or in shelter, $\mathrm{n}(\%)$ & $72(14.9 \%)$ & $10(19.2 \%)$ & $62(14.4 \%)$ & .35 \\
\hline Private health insurance, $\mathrm{n}(\%)$ & $65(13.5 \%)$ & $6(11.5 \%)$ & $59(13.7 \%)$ & .15 \\
\hline \multicolumn{5}{|l|}{ Total monthly income, $\mathrm{n}(\%)$} \\
\hline$\leq \$ 250$ & $104(21.9 \%)$ & $13(26.0 \%)$ & $91(21.4 \%)$ & .70 \\
\hline$\$ 251-\$ 750$ & $132(27.8 \%)$ & $12(24.0 \%)$ & $120(28.2 \%)$ & .70 \\
\hline$\$ 751-\$ 1500$ & $143(30.1 \%)$ & $13(26.0 \%)$ & $130(30.6 \%)$ & .70 \\
\hline$>\$ 1500$ & $96(20.2 \%)$ & $12(24.0 \%)$ & $84(19.8 \%)$ & .70 \\
\hline Health status: EUROQOL ${ }^{7}(0$ to 100$)$, mean (SD) & $70.0(20.3)$ & $71.5(21.4)$ & $69.8(20.1)$ & .58 \\
\hline Depressive symptoms (PHQ98 total score), mean (SD) & $7.9(6.6)$ & $7.4(6.7)$ & $7.9(6.6)$ & .52 \\
\hline Anxiety symptoms (OASIS ${ }^{9}$ score), mean (SD) & $5.5(5.4)$ & $5.5(5.2$ & $5.5(5.5)$ & .78 \\
\hline Employed full-time or part-time, n (\%) & $139(28.8 \%)$ & $13(25.0 \%)$ & $126(29.2 \%)$ & .76 \\
\hline Unemployed & $340(70.4 \%)$ & $39(75.0 \%)$ & $301(69.8 \%)$ & .76 \\
\hline Reported illegal income, $\mathrm{n}(\%)$ & $44(9.1 \%)$ & $4(7.7 \%)$ & $40(9.3 \%)$ & $>.99$ \\
\hline Unhealthy alcohol use (AUDIT-C ${ }^{10}$ positive), $n(\%)$ & $304(62.9 \%)$ & $33(63.5 \%)$ & $271(62.9 \%)$ & .93 \\
\hline Drug use consequences (SIP-D ${ }^{11}$ score, 0-15), mean (SD) & $11.2(11.1)$ & $9.5(12.6)$ & $11.4(13.2)$ & .08 \\
\hline Drug use severity (Global ASSIST score), mean (SD) & $21.3(17.7)$ & $19.3(14.9)$ & $21.5(18.0$ & .31 \\
\hline Number of days used in past $30^{a}$ & $14(4-28)$ & $2(2-4)$ & $16(6-29)$ & $<.001$ \\
\hline \multicolumn{5}{|l|}{ Drug of most concern, $\mathrm{n}(\%)$} \\
\hline Marijuana & $316(65.4 \%)$ & $25(48.1 \%)$ & $291(67.5 \%)$ & $<.001$ \\
\hline Opioids & $72(14.9 \%)$ & $7(13.5 \%)$ & $65(15.1 \%)$ & .76 \\
\hline Cocaine & $88(18.2 \%)$ & $20(38.5 \%)$ & $68(15.8 \%)$ & $<.001$ \\
\hline Other & $7(1.4 \%)$ & $0(0.0 \%)$ & $7(1.6 \%)$ & $>.99$ \\
\hline
\end{tabular}


Table 2. Patterns of Drug Use at 6 Months by Baseline Status

\begin{tabular}{|c|c|c|c|}
\hline \multirow{2}{*}{$\begin{array}{l}\text { Use Pattern for the Last } \\
30 \text { Days, } 6 \text { Months After } \\
\text { Baseline, } n(\%)\end{array}$} & \multicolumn{2}{|c|}{ Baseline Use Pattern } & \multirow[b]{2}{*}{$\begin{array}{c}P \\
\text { Value }\end{array}$} \\
\hline & $\begin{array}{c}\text { Weekend } \\
\text { Only }(n=52)\end{array}$ & $\begin{array}{l}\text { Not Weekend } \\
\text { Only }(n=431)\end{array}$ & \\
\hline No use ${ }^{a}$ & $14(26.9)$ & $56(13)$ & \\
\hline Weekend-only use & $10(19.2)$ & $22(5.1)$ & \\
\hline Not-weekend-only use & $28(53.9)$ & $353(81.9)$ & $.001^{b}$ \\
\hline \multicolumn{4}{|c|}{$\begin{array}{l}\text { among participants with drug use at baseline. } \\
\text { b Overall chi-square test of association. Subsequent post-hoc tests suggest significant differences for } \\
\text { each category } 6 \text { months later. }\end{array}$} \\
\hline
\end{tabular}

using drugs on other days of the week, and $14(26.9 \%)$ reported abstinence $(P=.001)$ (Table 2).

In unadjusted analyses, we found no significant differences between groups (Table 3). In adjusted analyses, the weekend-only pattern was associated with lower odds of any increase in days of use of the drug of most concern. The association between weekend-only drug use and any increase in severity, as measured by the global ASSIST score, was of similar magnitude, but results were not statistically significant. There was no significant association between weekend-only use and drug use consequences.

\section{DISCUSSION}

The majority of primary care patients with weekendonly drug use at baseline reported weekday use 6 months later, while weekday users largely maintained their use pattern. These findings suggest the importance of periodic monitoring of "recreational" drug use. A single-question standardized screen can be used to elicit necessary information. ${ }^{2}$ Primary care clinicians are in a position to support positive behavior change ${ }^{3}$ as well as to address increases in drug use intensity as an integral part of their role. ${ }^{13}$

This study has some important limitations, including its small sample size and the limitation of data by the purposes of the original study. We would have liked, for example, to have information to correlate weekend-only use with employment patterns. Also, the participants enrolled in this study were typical of an inner-city population with recent drug use, and findings may not be generalizable to other settings. Despite these limitations, this analysis provides a window into changes in patterns of "less severe" recreational drug use over time.

Table 3. Associations Between Weekend-Only and Not-Weekend-Only Drug Use and Any Increase in Severity, Days of Use of Drug of Most Concern, and Drug Use Consequences

\begin{tabular}{|c|c|c|c|c|c|c|}
\hline \multirow[b]{2}{*}{ Outcomes } & \multicolumn{2}{|c|}{ Proportions With Outcome } & \multicolumn{4}{|c|}{ Odds Ratios, Weekend-Only vs Not-Weekend-Only } \\
\hline & $\begin{array}{l}\text { Weekend } \\
\text { Only Use } \\
(n=52)\end{array}$ & $\begin{array}{l}\text { Not Weekend } \\
\text { Only Use } \\
(n=431)\end{array}$ & $\begin{array}{l}\text { Unadjusted Odds } \\
\text { Ratio, OR ( }(95 \% \mathrm{CI})\end{array}$ & $\begin{array}{c}P \\
\text { Value }\end{array}$ & $\begin{array}{c}\text { Adjusted Odds } \\
\text { Ratio, AOR ( } 95 \% \mathrm{Cl})\end{array}$ & $\begin{array}{c}P \\
\text { Value }\end{array}$ \\
\hline Increase in drug use severity ${ }^{b}$ & $44 \%$ & $56 \%$ & $0.62(0.35-1.12)$ & 0.11 & $0.56(0.30-1.04)$ & 0.07 \\
\hline $\begin{array}{l}\text { Increase in number of days per month } \\
\text { of use of drug of most concernc }\end{array}$ & $37 \%$ & $35 \%$ & $1.09(0.60-1.98)$ & 0.78 & $0.48(0.25-0.94)$ & 0.03 \\
\hline Increase in drug use consequences ${ }^{d}$ & $26 \%$ & $29 \%$ & $0.84(0.43-1.63)$ & 0.60 & $0.81(0.41-1.59)$ & 0.54 \\
\hline
\end{tabular}




\section{CONCLUSIONS}

Recreational users have lower odds of increasing drug use than weekday users, and potentially lower odds of increasing drug use severity. However only a fifth of those who initially reported weekend-only drug use retained that pattern at six-month follow-up; while some abstained, most shifted to include weekday drug use. These findings suggest caution in accepting recreational drug use as reassuring, and the importance of following patients in whom drug use is identified.

To read or post commentaries in response to this article, see it online at http://www.annfammed.org/content/13/3/257.

Funding support: Supported in part by a grant from NIH/NIDA R01DA025068

Key words: recreational drug use; consequences of drug use; days of drug use; drug severity; primary care

Submitted June 22, 2014; submitted, revised, October 15, 2014; accepted October 23, 2014.

\section{REFERENCES}

1. Manwell LB, Fleming MF, Johnson K, Barry KL. Tobacco, alcohol, and drug use in a primary care sample: 90 -day prevalence and associated factors. J Addict Dis. 1998;17(1):67-81.

2. Friedmann PD, McCullough D, Saitz R. Screening and intervention for illicit drug abuse: a national survey of primary care physicians and psychiatrists. Arch Intern Med. 2001;161(2):248-251.

3. Measham F, Williams L, Aldridge J. Marriage, mortgage, motherhood: what longitudinal studies can tell us about gender, drug 'careers' and the normalisation of adult 'recreational' drug use. Int J Drug Policy. 2011;22(6):420-427.
4. Saitz R, Palfai TP, Cheng DM, et al. Screening and brief intervention for drug use in primary care: the ASPIRE randomized clinical trial. JAMA. 2014;312(5):502-513.

5. Humeniuk R, Ali R, Babor TF, et al. Validation of the alcohol, smoking and substance involvement screening test (ASSIST). Addiction. 2008;103(6):1039-1047.

6. Westerberg VS, Tonigan JS, Miller WR. Reliability of form 90D: An instrument for quantifying drug use. Subst Abus. 1998;19(4):179-189.

7. EuroQol Group. EuroQol-a new facility for the measurement of health-related quality of life. Health Pol. 1990;16(3):199-208.

8. Kroenke K, Spitzer RL, Williams JB. The PHQ-9: validity of a brief depression severity measure. J Gen Intern Med. 2001;16(9):606-613.

9. Norman SB, Cissel SH, Means-Christensen AJ, Stein MB. Development and validation of an Overall Anxiety Severity and Impairment Scale (OASIS). Depress Anxiety. 2006;23(4):245-249.

10. Bush K, Kivlahan DR, McDonell MB, Fihn SD, Bradley KA. The AUDIT Alcohol Consumption questions (AUDIT-C): an effective brief screening test for problem drinking. Ambulatory Care Quality Improvement Project (ACQUIP). Alcohol Use Disorders Identification Test. Arch Intern Med. 1998;158(16)1798-1795.

11. Alterman Al, Cacciola JS, Ivey MA, Habing B, Lynch KG. Reliability and validity of the alcohol short index of problems and a newly constructed drug short index of problems. J Stud Alcohol Drugs. 2009;70(2):304-307.

12. Saitz R, Cheng DM, Allensworth-Davies D, Winter MR, Smith PC. The ability of single screening questions for unhealthy alcohol and other drug use to identify substance dependence in primary care. J Stud Alcohol Drugs. 2014;75(1):153-157.

13. Chen K, Kandel DB. The natural history of drug use from adolescence to the mid-thirties in a general population sample. Am J Public Health. 1995;85(1):41-47. 